\title{
Engaging Students in the Undergraduate Analytical Decision Making Course
}

\author{
Mary Malliaris, Loyola University Chicago, USA \\ Faruk Guder, Loyola University Chicago, USA
}

\begin{abstract}
There are many voices today discussing the necessity of changing the ways we teach, for example, Gen Y studies about the way students learn, employers' lists of skills they say current graduates need, and colleges that desire to always improve how they deliver information. These have led to classes where the learning styles are more hand-on, less lecture-focused, and more engaging for the Gen Y learner. The purpose of this paper is to give an illustration of how an analytics class can be restructured to address these issues. We develop an undergraduate class that focuses not only on analytical methods, but also on presentation, writing, and team skills. These are all developed within the framework of an original student research project.
\end{abstract}

Keywords: Engaged Learning; Teamwork; Communication Skills; Analytics

\section{INTRODUCTION}

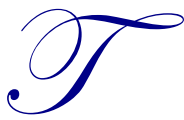

he Gen Y student was born between the 1980's and 2000. They have been digitally connected all their lives and spend their waking moments multitasking. They use their smartphone as a watch, an alarm clock, a newspaper, a search engine, and a music device. They are always in touch with friends through social media sites such as Facebook, Twitter, and text messaging. They must cope with massive amounts of information continuously arriving from different sources, and learn how to quickly evaluate it. Group decisions are second nature and everyone voices an opinion. Even with the best of professors at the best universities, they zone out during lectures. Prensky (2001) discusses how the brain of this group is different, and teachers must change in order to teach them. Prensky points out that today's students grew up using computers, smart phones, video games, which caused a shift in how they learn. Today's teachers must adjust their teaching styles and content to create better learning environments for today's students. Risko el at (2012), in a study of student during lecture-style courses, found that "mind wandering increases with time on task and memory for the lecture material decreases". Their study involved two experiments wherein participants watched a video recorded lecture alone or in a classroom. Seal, Przasnyski and Leon (2010) used screen capture technology to design interactive support and found that interactive tutorials improved students' understanding of modeling of transportation problem in a spreadsheet.

Colleges are making the transition to courses that require more interaction in the classroom and less lecturing. Faculty have not themselves learned with this methodology so this necessitates training for them and encouragement for them to enter this new territory. Classes in the new styles are called various names, including flipped classes, engaged learning classes, and experiential learning. The method used in these classes, where students play a dynamic part in their learning experience, can also be called active learning. Riddle (2010) walks through an example of active learning in teaching linear programming (LP). Riddle's active learning exercise involved the introduction of the algebraic formulation of LP model and provided a foundation to solve LP models. The results showed strong performance by the students in LP formulation. Clark \& White (2010) argue for the value of experiential learning that involved a business strategy sponsored by the students that has the involvement of managers from four major corporations. Some of the benefits reported are that the networks that they built, the interview opportunities that they received from the participating companies and the opportunity to apply the knowledge they are learning in classes. Gorman (2012) used the game (The Pass the Pig) observed that using an engaging game helped students to improve their problem-solving and analytical skills in one class session. 
Grossman (2006) covers in depth a way to use spreadsheets to enhance germaneness of a management science course. He emphasizes the importance of learning in the context of solving a problem.

Our university has established a Center for Experiential Learning to increase the number of courses of this type. This Center offers training for any faculty who need assistance moving their class into an experiential area, and also sponsors student activities such as the Weekend of Excellence. During this weekend, usually in late April, all undergraduates who have worked on any research project are given the opportunity to present their work, either orally or in a poster session.

This paper gives an overview of our undergraduate engaged learning Analytical Decision Making course. This course was designed to address the demands of employers, students, and the university for courses that involve students in their learning and that give them the skills they need to do well in today's companies.

\section{Engaged Learning}

Beginning in the Fall semester of 2012, all undergraduates at our university were required to have at least one engaged learning class during their time as an undergraduate. In order to provide these opportunities for students, each school was asked to create classes in the engaged learning style. In general, classes that can be considered engaged learning must include the following:

- $\quad$ A structured learning experience integrated into a course that engages students in learning outside the classroom, such as in a community agency, professional organization, or in a research setting;

- $\quad$ Critical reflection on that experience through various assignments in class; and

- $\quad$ Synthesis of the experience through a final project or portfolio

The University has an office of Engaged Learning that offers guidance and training to faculty wishing to take up this challenge. The Engaged Learning Sub-Committee must approve all courses for designation as satisfying the engaged learning requirementThere are five different categories of classes that satisfy the Engaged Learning requirement: Service-Learning, Academic Internship, Field Work, Undergraduate Research, and Public Performance. The business school has engaged learning courses in all categories except public performance. The current list of courses includes Business Internship, Project Leadership, Social Entrepreneurship, Micro-Enterprise Consulting, Research Practicum, Requirements Analysis \& Communication, and our capstone Entrepreneurship Strategies. Recently added to this list was our course on Analytical Decision-Making.

Some of the reasons for the move to engaged learning courses were the numerous studies about the changing ways that students learn best, and the changing emphasis from employers concerning the importance of communication skills and analysis skills. The process of learning varies among students as individuals have different learning preferences. Coffield et al (2004) discuss learning styles and their implications for pedagogy. But regardless of a student's learning style, the review of the literature and research on learning shows that the students learn best if they are actively engaged in the process of learning. McCune \& Entwistle (2011) also discuss the importance of developing the will to learn.

Employers have switched their demands from just area-specific knowledge to teamwork, leadership, analytical savvy, and communication skills. Interviews have moved from focusing on grade point average and specific courses taken to case analysis. They want to see how the student thinks, reasons their way through a problem, and handles missing information. Interviews may consist of many rounds, each with a different person and personality in the company. Employers generally look for soft skills, in addition to topic knowledge, in new graduates who will be successful in their careers. In a 2011 Michigan State University survey discussed in Crawford et al (2011), employers and alums ranked soft skills such as communication and decision making/problem solving as the two most important skills. Self-management ranked third most important in the soft skills list. Thompson et. al. (2012) illustrate the advantages of group presentations where the students must argue for and defend their position. Hart Research (2007), Susan Adams in Forbes (2013), and the Nation Association of Colleges and Employers (2013) have all reinforced the findings from Michigan State. Employers today are looking for graduates who are already skilled in teamwork, analytical skills, and various types of communication. Whereas in a class, students must often be persuaded of the importance of team work (Rassuli \& Manzer, 2005). 
In our recent undergraduate curriculum review process, the feedback we obtained from employers about our undergraduate programs echoed these same perspectives. Our focus groups identified the most important skills to be: interpersonal skills such as communication (particularly written), analytical and problem solving skills, team skills, and self-motivation. Decision making skills, also high on the list of desired attributes of graduates, involves identifying and analyzing problems, taking appropriate actions, creating solutions and applying the knowledge learned to other problem cases.

\section{THE COURSE STRUCTURE}

\section{Objectives and Background}

This class is a 300-level class, which means that it is open only to juniors and seniors. It has a pre-requisite of the introductory information systems class, which gives them uniform skills in Excel and Access, and the core statistics class.

We wanted the course to give the students the opportunity to practice a number of skills: oral presentation of technical data, written communication, working in a team for a common goal, conducting an original research study, presenting results to a wide audience, and understanding analytical research studies. So the course had to have regular opportunities to practice these skills and the grading also needed to reflect their importance.

In addition, we had a body of knowledge to cover relating to Analytics. This included modules for nine typical data mining methodologies that they would find useful in analyzing the data sets for their research projects. We also wanted to develop skills in using IBM's SPSS Modeler for the data analysis.

Classes were held once a week for $21 / 2$ hours for 15 weeks, and met in a room that had a computer available for each student. Because the class has a writing intensive component, the university caps the enrollment at 24 students.

\section{Grading Criteria}

The criteria used for grading are listed in Table 1. These emphasize weekly writing and analysis opportunities, plus the requirement to create an original research paper as a team and present it to a wide audience. Because the class required a team project and presentation at the undergraduate symposium, some of the points needed to come from teamwork. However, in order to prevent the problem of having one team member riding on the work of others, in-class writing assignments alternated between individual and team writing. In one week, students would write an individual section of their project paper. This individual assignment was graded and returned. The following week, the team members merged their sections into one and this time, the grade was given to the team.

Table 1. Grading criteria for the course

\begin{tabular}{l|c}
\hline Twelve in-class writing assignments & $120(10$ points each $)$ \\
\hline Twelve homework case paper writing assignments & $120(10$ points each $)$ \\
\hline Initial presentation in class & 20 \\
\hline Final presentation in class & 40 \\
\hline Final paper & 80 \\
\hline Team member comments on your work & 5 \\
\hline Presentation at the symposium & 15 \\
\hline Final Exam & 60 \\
\hline Total & 460 \\
\hline
\end{tabular}

Presentations of their projects occurred in three phases. Mid-way through the term, each team gave a brief presentation that focused only on their data set and problem. Near the end of the term, teams gave a complete final presentation. All class members were encouraged to give constructive criticism each time that would help each team improve their final presentation, however, all grading points were awarded by the instructor. Finally, at the 
symposium, teams had one last opportunity to present their work, here to a wide audience from diverse backgrounds. Judges from different disciplines throughout the university submitted written evaluations to each team about their work, but points for the presentation where determined solely by the class instructor.

\section{A Typical Class}

The first half of class began with a discussion of the analytical technique of the week and the structure of a data set necessary for that technique. This was followed by hands-on work with IBM's SPSS Modeler data mining package. Using Modeler and a data set optimized for the technique, the students set up and ran a model, and analyzed the results. This sometimes required data manipulation in Excel and Access to get the data set in the correct format for the model to use. The second half of class focused on two parts: the discussion of the weekly case paper, and an in-class writing exercise.

Students were divided into two groups for a weekly paper discussion, Group A and Group B. Prior to each class, students were given a research paper (downloaded from Google Scholar) to read and analyze. This paper used the methodology that was being discussed that week, for example, Association Analysis or Cluster Analysis. Students were required to read and understand a paper using a methodology with which they had no experience. This process made it very clear to them whether or not the paper had done a good job explaining the methodology and the reason for using it. Since they were ultimately going to be presenting their research to an audience who had not taken this course (at the yearly undergraduate symposium) it was an important exercise for them to read ideas they were not familiar with. It helped them understand the position that the audience was going to be in for their presentations. If the student was in group A, they had to write a one-page description of the paper's purpose, methodology and findings, as though they were the author. Those in group B wrote a criticism of the paper, as though they were a journal editor. Students alternated being in group A and group B each week. These papers were due before class began.

During class, the groups organized a brief presentation, then came to the front of the class. Each person in group A presented one positive aspect of the paper to the group, and each person in group B criticized some aspect of the paper. For example, a group A student might begin with "The primary question I tried to answer was..., I used data from ... and derived the following columns for the study..., The methodology I used was... because..., My major contribution was...". Group B students might respond with criticisms of the type "This is a misleading title because..., The authors actually answered a different question than the one they posed in the introduction..., The weakest point in the analysis was...".

This weekly exercise gave them practice in presenting and analyzing technical information and in defending their position. Because they had not actually written the paper, it was easy for them to accept the criticism of their peers. This process was a surprise and delight to them to find that they were encouraged to find the weak points and comment on them. Students are often given things to read and it is assumed that whatever is written is correct. By allowing them the freedom to criticize papers, they took much more interest in what the paper said and read it very closely. Most students said they preferred the times they got to be on the critical side because it opened their eyes to the weaknesses in the writing.

Following this, the last portion of class focused on the original research paper they were writing for presentation at the Undergraduate Research Symposium. This symposium is held each Spring near the end of the semester and is organized by the University. Undergraduates have the opportunity to present their research in one of two venues, in a poster session, or in an oral presentation. For this original research study, students were divided into teams of three. They were allowed to select their own question, and were responsible for finding an appropriate data set as long as it was sufficiently large and complex. The data set and general guiding question had to be determined by the second week of class, and approved by the instructor. There was much opportunity to refine the question and to format the data to fit the technique they ultimately decided to use.

This research portion of the class was focused each week on a particular piece of the research study. We began with a discussion of the purpose of this part of the study, tips about writing, and discussion about which previous papers they read that did this well or poorly and why. Then, the students wrote, in-class, this portion of 
their paper. This writing was done individually some weeks, and as a team on other weeks. For example, one week they wrote individually about the problem statement, the following week was an individual writing assignment on their literature review. These were followed by a team rewrite of their problem statement and literature review on the following week. Each week's writing was returned to them with comments and corrections which helped them perfect what they were trying to say. Each team also had the opportunity to see their ideas expressed from three points of view and combine those into one coherent piece of writing using the best parts from each team member's writing.

The time-line forced them to move fairly rapidly through the process of constructing their research paper. Students frequently met outside of class to play with their data set in Modeler and discuss what they were finding. This process concluded prior to the symposium with a class day devoted to presentations by each team to the entire class. The class asked questions of the group presenting at the end of each talk and also wrote up commentaries for each team about the parts of the study that were done best and that needed refining. Given their weekly practice doing this for numerous research studies, they gave very insightful comments that helped each team tweak their presentations for their final performance at the symposium.

\section{The Final Exam}

The structure of the final needed to mirror what had been asked of the students during the class. The country had just gone through March madness, and many students had followed the proceedings avidly. So, we thought that a basketball themed challenge might be appealing to the students. Two weeks prior to the final, students were asked to read and analyze a paper about the relationship of technical fouls to player performance. This was the last paper discussed and presented in class. Students were also given a data set with all professional NBA player data from the 2010, 2011, and 2012 seasons. The challenge was to find some interesting pattern in the data set using any data mining technique studied during the semester. Small prizes were announced and would be given to the $1^{\text {st }}, 2^{\text {nd }}$, and $3^{\text {rd }}$ place winners. It was, of course, not just the prize, but the winning that appealed to them. Students gave an oral presentation of the question they addressed, the data manipulation (some had additional data), the methodology, the results, and the implications of their findings. They were required to turn in their data set, PowerPoint slides, methodology, analysis, and summary for grading prior to this last class. After all presentations and questions, each student voted for first and second places. They could not vote for themselves in order give a ranking with perhaps less self-interest. Votes were tallied at the time, and prizes awarded. Instructor grading was done later and addressed some finer points of the analysis and presentation. The winning presentation used neural networks to compare actual NBA spending per player position with the most important characteristics of the players per position. They found that there are discrepancies between what performance characteristics determine the salary of an NBA player and what performance characteristics determine the actual player performance as measured by playoff appearances. For example, one of the most important characteristic in determining small forward salaries is offensive performance. But, the most important characteristics in determining whether a small forward makes it to the playoffs is combined offensive and defensive performance. Thus their conclusion was that NBA teams are not spending their money as wisely as they could.

\section{KEY APPLICATIONS FOR TEACHING}

The students used real data sets of their choosing for their projects. Being allowed to choose this focus rather than to be assigned to a problem elevated the process above the level of usual homework. Students were more invested in finding a solution to something that interested them, and answering a problem gave them a real sense of discovery.

Reading and analyzing published case studies helped the students to develop confidence in their abilities to understand new techniques. In the field of analytics, where new approaches and methodologies are evolving consistently, this can be an especially important skill to develop. Because they had to evaluate the case, and write about it, before the technique was discussed in class, this forced them to ask what the methodology was attempting to do and how. It also gave them insight into what comprised good and bad writing about technical topics. Students also felt better prepared to follow the presentations given at the symposium by students outside their areas, and to analyze what others had done. 
Being asked to criticize other's research as journal editors helped students see weak points in their own writing and analysis. Students began this process hesitantly at the beginning of the semester, but by the end, felt unafraid to read and challenge published papers. As future analysts, the ability to see what is not working is often as valuable as the ability to see what is.

Being asked to present other's research as their own gave the students the opportunity to learn how to talk about technical results and well as how to accept criticism in a non-threatening way. Since they had not actually written the paper, they could hear and respond to the criticisms without feeling vulnerable.

Having the opportunity to practice their presentations in front of their peers and receive friendly suggestions gave them more confidence before their university presentation. They each had the chance to learn about their presentation strengths and to work on their weaknesses. Many found that rehearsing not only made them more confident, but increased their enjoyment in the presentation process.

\section{SUMMARY}

In this paper, we presented an example of an analytical decision making course that has been constructed to draw the student into creating his/her own experience from the first day of class. Through regular and repeated exercises each week, the students were able to improve their oral and written presentation skills. The research project allowed them to practice team skills, while the structure of the exercises avoided having non-working team members. Each individual student had to write every piece of the research paper. These were graded and returned, then combined as a team during the in-class writing exercise into an optimal section.

Because graded in-class exercises occurred every week, both oral and written, attendance was not a problem. However, we believe that the class built around student activity was the real reason for student involvement. It is not just students, but also faculty who become converted by exposure to these new ways of engaged learning and teaching.

\section{AUTHOR INFORMATION}

Mary Malliaris is the Chair of Information Systems \& Operations Management department and Professor of Information Systems in the Quinlan School of Business at Loyola University Chicago. She teaches courses in the area of data analysis including data mining, informatics, financial modeling, and statistics. She has research interests in several areas including applications of neural networks, modeling financial markets, hospital professional practice environments and gender in IT.

Faruk Guder is Associate Dean and professor of Operations Management in the Quinlan School of Business at Loyola University Chicago. He teaches courses in the areas of operations management, quality management, and statistics. His research interests are in the areas of quality management, inventory management, and distribution facilities location in a price-responsive environment.

\section{REFERENCES}

Adams, S (2013). “The 10 Skills Employers Most Want in 20-Something Employees”, downloaded April 30, 2013 retrieved from http://www.forbes.com/sites/susanadams/2013/10/11/the-10-skills-employers-most-want-in20-something-employees/

Clark, J., \& G. White (2010). "Experiential Learning: A Definitive Edge in The Job Market". American Journal of Business Education, 3(2), 115-118.

Coffield, F., D. Moseley, E. Hall, and K. Ecclestone (2004). Learning Styles and Pedagogy in Post-16 Learning. A Systematic and Critical Review. London: Learning and Skills Research Centre.

Crawford, P., S. Lang, W. Fink, R. Dalton, and L. Fielitz (2011) Comparative Analysis of Soft Skills: What is Important for New Graduates?, Washington, DC: Association of Public and Land-grant Universities, retrieved from http://www.aplu.org/document.doc? id $=3414$

Gorman, M. (2012). Analytics, Pedagogy and the Pass the Pigs Game. INFORMS Transactions on Education, 
13(1), pp. 57-64.

Grossman, T. (2006). Integrating Spreadsheet Engineering in a Management Science Course: A Hierarchical Approach. INFORMS Transactions on Education, 7(1), pp. 18-36.

Hart Research Associates, (2007) on behalf of The Association Of American Colleges And Universities, How Should Colleges Prepare Students To Succeed In Today's Global Economy?, retrieved from http://www.aacu.org/leap/students/employerstopten.cfm

McCune, V., and N. Entwistle (2011) Cultivating the Disposition to Understand in 21st Century University Education, Learning and Individual Differences, 21 (3), 303-310, ISSN 1041-6080, http://dx.doi.org/10.1016/j.lindif.2010.11.017.

National Association of Colleges and Employers (2013), "Job Outlook: The Candidate Skills/Qualities Employers Want", retrieved from https://www.naceweb.org/s10022013/job-outlook-skills-quality.aspx

Prensky, M. (2001). Digital Natives, Digital Immigrants, On the Horizon, 9 (5).

Rassuli, A. and J. Manzer (2005), "Teach Us to Learn": Multivariate Analysis of Perception of Success in Team Learning, Journal of Education for Business, 81 (1), 21-27.

Riddle, E., (2010). An Active Learning Exercise for Introducing the Formulation of Linear Programming Models, Decision Sciences Journal of Innovative Education, 8 (2), 367-372.

Risko, E., N. Anderson, A. Sarwal, M. Engelhardt, and A. Kingstone (2012). Everyday Attention: Variation in Mind Wandering and Memory in a Lecture, Applied Cognitive Psychology, 26, 234-242. DOI: 10.1002/acp.1814

Seal, K., Z. Przanyski and L. Leon (2010). How Levels of Interactivity in Tutorials Affect Students' Learning of Modeling Transportation Problems in a Spreadsheet", Decision Sciences Journal of Innovative Education, 8 (1), 75-94.

Thompson, K, B. Switky, B, and A. Gilinsky (2012), Impromptu Presentations: Boosting Student Learning and Engagement through Spontaneous Collaboration, Journal of Education for Business, 87 (1), 14-21. 
NOTES 